\title{
Plant-Based Culture Media for Improved Growth and Sporulation of Cercospora janseana
}

\author{
Sai Sree Uppala, ${ }^{1}$ Xin-Gen Zhou, ${ }^{1, \dagger}$ Baohua Liu, ${ }^{2}$ and Mingliang $\mathrm{Wu}^{2}$ \\ ${ }^{1}$ Texas A\&M University System, AgriLife Research and Extension Center, Beaumont, TX, U.S.A.; and ${ }^{2}$ Hunan Agricultural Uni- \\ versity, Changsha, Hunan, China
}

\begin{abstract}
Cercospora janseana is the causal agent of narrow brown leaf spot, one of the major diseases of rice in the United States. In vitro studies were conducted to evaluate various plant-based agar media in comparison with potato dextrose agar (PDA) for their effects on radial growth and sporulation of $C$. janseana. The agar media were evaluated individually with the following plant-extract ingredients: fresh rice leaves, dried rice leaves, dried rice stems, dried rice roots, dried rice hulls, dried rice straw, rice bran, dried sorghum leaves, and dried barnyard grass leaves. Plantbased extracts obtained from $25,50,100$, or $200 \mathrm{~g} /$ liter (plant material/ water) were tested either alone or in combination with 10 and $20 \%$ clarified V8 juice. PDA served as the control medium. Media with 10 and $20 \%$ V8 juice were also included for comparison. Media were inoculated

with a disc of 1-week-old actively growing $C$. janseana at the center of Petri plates and incubated at $28^{\circ} \mathrm{C}$ with a 12/12-h (light/dark) cycle for 2 weeks. Radial growth was measured at 7 and 14 days after inoculation (DAI), whereas sporulation was measured at 14 DAI. Radial growth and sporulation differed among various media and their amendment concentrations. Media with extracts of fresh rice leaves, dried rice leaves, dried rice stems, dried barnyard grass leaves, and clarified V8 juice enhanced radial growth compared with the PDA control. Of all the agar media evaluated, fresh rice leaf extract amendment at $25 \mathrm{~g} /$ liter with no V8 supplementation consistently supported the greatest radial growth, and $10 \%$ V8-only medium resulted in greater sporulation of $C$. janseana than other media evaluated.
\end{abstract}

Cercospora janseana (Racib.) O. Const. (syn. Cercospora oryzae Miyake; teleomorph Sphaerulina oryzina K. Hara) is the fungal pathogen that causes narrow brown leaf spot (NBLS), an economically significant disease in rice. The association of NBLS pathogen with rice plants was independently discovered by Raciborski from Java in 1900 (Raciborski 1900) and Metcalf from North America in 1906 (Metcalf 1906). The pathogen was originally named Napicladium janseanum by Raciborski (Ou 1985). However, Miyake was the first to describe this disease and named the fungus $C$. oryzae Miyake (Miyake 1910). In 1982, the fungus was renamed as C. janseana (Racib.) O. Const by Constantinescu (Constantinescu 1982). NBLS was first reported in the United States in 1937 (Ou 1985). At present, NBLS occurs in almost all major rice-growing regions of the world, except Europe (Ganguly 1946; Groth and Lee 2003; Overwater 1960; Ryker and Jordon 1940; Tuli et al. 2017).

NBLS historically was considered a minor disease owing to its sporadic occurrence in the United States. However, in recent years, the occurrence and severity of NBLS have increased in Louisiana, Texas, and Arkansas (Groth 2007, 2008; Yingling et al. 2007; Zhou and Jo 2014). This disease became more severe especially when warm springs and wet summers were coupled with excessive overwintered inoculum and large acreage of susceptible cultivars (Groth 2007, 2008; Yingling et al. 2007; Zhou and Jo 2014). NBLS symptoms manifest on the leaves, sheaths, internodes, and panicles of the rice plant. On the leaves and sheaths, the symptoms include narrow, brown, elongated, linear, reddish-brown lesions ranging from 2 to $12 \mathrm{~mm}$ in length and 1 to $2 \mathrm{~mm}$ in width running parallel to the leaf veins (Groth and Lee 2003; Zhou and Jo 2014). As the disease progresses, net blotch or brown blotch symptoms occur on leaf sheaths owing to the browning of veins on tan to yellow discolored leaf sheaths. Light brown to tan discoloration of the internodal areas at the base of the panicle is another symptom of NBLS. Under

${ }^{\dagger}$ Corresponding author: Xin-Gen (Shane) Zhou;

E-mail:xzhou@aesrg.tamu.edu

Accepted for publication 6 September 2018.

() 2019 The American Phytopathological Society conducive conditions, NBLS causes grain discoloration, premature ripening, chalkiness, reduced milling recovery, and lodging of plants, especially on extremely susceptible cultivars (Ryker and Jordon 1940; Zhou and Jo 2014). The control of NBLS has been primarily through race-resistant cultivars. However, $C$. janseana is highly variable in pathogenicity, and cultivar resistance often breaks down owing to the genetic adaptation of the fungus and the development of new physiological races (Chilton and Tullis 1946; Estrada et al. 1981; Groth and Lee 2003; Ryker and Jordon 1940; Sah and Rush 1988). Therefore, fungicides remain as an important option for control of this disease (Mani et al. 2016; Uppala and Zhou 2018).

Culturing and conidial production of $C$. janseana inoculum for laboratory and field studies is crucial to better understand the biology and epidemiology of NBLS, screen rice germplasm for resistance, and develop effective disease management strategies. $C$. janseana grows slowly and does not sporulate well on potato dextrose agar (PDA) (Kaur and Hollier 2013; Mew and Gonzales 2002). The development of plant-based culture media to improve growth and sporulation of various species of Cercospora has been carried out. These include the extracts of peanut leaves (Abdou and Cooper 1974) and hulls (Starkey 1980) for sporulation of C. arachidicola; soybean and crape myrtle leaf extracts for sporulation of C. kikuchii (El-Gholl et al. 1982); green corn leaves, senescent corn leaves, and V8 juice for sporulation, spore germination, and germ tube growth of C. zeaemaydis (Beckman and Payne 1983; Brunelli et al. 2006); and V8 juice for radial growth and spore germination of $C$. beticola (Secor and Rivera 2012). Plant-based media can also be cost-effective compared with commercially available dehydrated culture media (Basu et al. 2005; Jha and Dikshit 2017; Osman et al. 2013). In the current study, we evaluated various plant-based agar media in comparison with PDA for their effects on radial growth and sporulation of $C$. janseana.

\section{Materials and Methods}

Fungal strain. Isolate BMT-41 of $C$. janseana was used in this study. This isolate was recovered from a rice leaf showing symptoms of NBLS in Beaumont, Texas, in 2011. The culture was maintained on Difco PDA (Beckton, Dickinson and Company, Sparks, MD).

Effects of plant-based media and amendment concentrations on radial growth of $C$. janseana (experiment 1 ). In this study, plant extracts obtained from the following plant materials were evaluated 
individually in an agar medium: fresh rice leaves, dried rice leaves, dried rice stems, dried rice roots, dried rice hulls, dried rice straw, dried sorghum leaves, and dried barnyard grass (Echinochloa crus-galli) leaves. Four concentrations $(25,50,100$, and $200 \mathrm{~g} / \mathrm{liter})$ of these plant materials were evaluated in the form of plant extracts. Rice (cultivar Presidio), barnyard grass, and sorghum (hybrid DKS 3707) at reproductive growth stages were collected from fields located at Texas A\&M AgriLife Research Center, Beaumont, Texas. Plant materials were thoroughly washed under running tap water and were partitioned into roots, stems, and leaves. For media with dried plant extracts, plant materials were dried at $70^{\circ} \mathrm{C}$ for $48 \mathrm{~h}$ and ground into powders. Individual plant extracts were obtained by processing the dried ground plant tissue powders or fresh rice leaves in a kitchen blender (Hamilton Beach Brands, Glen Allen, VA). For this, plant material $(25,50,100$, or $200 \mathrm{~g})$ was added to $750 \mathrm{ml}$ of deionized water, processed in a kitchen blender for $2 \mathrm{~min}$, and filtered through two layers of cheesecloth into a measuring cylinder. Plant material in the cheesecloth was moved to the blender, and $250 \mathrm{ml}$ of water was added; it was ground for $30 \mathrm{~s}$ and then filtered through two layers of cheesecloth into the same measuring cylinder that contained filtrate. At both these stages of grinding and filtering, the volume of the filtrates was less than the initial amount of water added, owing to the absorption by plant material. After the second grinding and filtering, water was poured through the plant material in the cheesecloth until the final volume of the filtrate was $1,000 \mathrm{ml}$. These filtrates were used as plant extracts or liquid source for agar media. Respective media were prepared by combining plant extracts with agar at $15 \mathrm{~g} /$ liter.

V8 medium from commercially available V8 juice (Campbell Soup Company, Camden, NJ), containing blends of tomatoes, carrots, celery, beets, parsley, lettuce, watercress, spinach, salt, ascorbic acid, and citric acid as major ingredients, was also evaluated in this experiment. V8 medium was prepared using the method described by Ferguson and Jeffers (1999). Calcium carbonate at the rate of $1 \%$ was added to commercially available V8 juice and centrifuged at $6,000 \mathrm{rpm}$ for $10 \mathrm{~min}$. The supernatant was collected as clarified V8 juice, and the pellet was discarded. Twenty percent V8 medium was prepared by adding $200 \mathrm{ml}$ of clarified V8 juice to $800 \mathrm{ml}$ of deionized water and $15 \mathrm{~g}$ of agar. PDA medium was included as a control. The $\mathrm{pH}$ of each medium was measured by a Mettler Toledo LE-438 pH meter (Mettler Toledo, Columbus, OH), and all media were autoclaved for $20 \mathrm{~min}$ at $121^{\circ} \mathrm{C}$. Autoclaved media were cooled to $50^{\circ} \mathrm{C}$ in a water bath, and filter sterilized $1 \mathrm{ppm}$ of thiamine (VWR International, Radnor, PA) and 2 ppm of streptomycin sulfate (Thermo Fisher Scientific, Waltham, MA) were added to the media and dispensed into sterile $60 \times 15-\mathrm{mm}$ Petri plates at $15 \mathrm{ml}$ per plate.

Each medium was inoculated in the center with a $0.6-\mathrm{cm}$ agar disc, topside down, from a 1-week-old PDA culture of C. janseana. Cultures were incubated at $28^{\circ} \mathrm{C}$ under diurnal fluorescent light (12/12-h light/darkness cycle) for 2 weeks. Each medium treatment was replicated three times. The treatments were arranged according to a splitplot design, with plant extracts evaluated as the main-plot factor and amendment concentration as the subplot factor. Radial growth was measured at 7 and 14 days after inoculation (DAI). For radial growth measurements, two perpendicular straight lines (diameters) were drawn on the bottom of each Petri dish containing fungal growth. The crossing point coincided with the center of the initial 0.6-cm fungal disc. Colony diameters were measured on the perpendicular lines, and mean colony diameter was obtained by averaging both transects. Net radial growth was obtained by subtracting $0.6 \mathrm{~cm}$ from the mean colony diameter. This experiment was conducted three times.

Effects of plant-based media in combination with V8 juice on radial growth and sporulation of $C$. janseana (experiment 2). This study was conducted to evaluate the effects of plant extracts in combination with clarified V8 juice on the growth and sporulation of $C$. janseana. Individual agar media were prepared using plant extracts (each at $25 \mathrm{~g} /$ liter) of fresh rice leaves, rice bran (stabilized rice bran from Bob's Red Mill, Milwaukie, OR), dried rice leaves, dried rice stems, and dried barnyard grass leaves, either alone or in combination with 10 or $20 \%$ clarified V8 supplementation. PDA and 10 and $20 \%$ V8 media without any plant extracts were included as the controls. All the media were prepared and inoculated with $0.6-\mathrm{cm}$ discs of actively growing $C$. janseana as described in experiment 1 . Inoculated plates were incubated at $28^{\circ} \mathrm{C}$ under diurnal fluorescent light $(12 / 12$ $\mathrm{h}$ light/darkness cycle) for 2 weeks. Each medium treatment was replicated three times. The treatments were arranged according to a splitplot design, with plant extracts evaluated as the main-plot factor and V8 supplementation level as the subplot factor. Radial growth measurements were taken at 7 and 14 DAI as described above. Conidial counts were obtained at 2 weeks after inoculation using a whole mycelium harvest technique. For each treatment, the whole culture of $C$. janseana (total growth of the fungus along with the medium) from each Petri plate was cut into small pieces using a heat-sterilized stainless-steel scalpel and placed into a sterile $15-\mathrm{ml}$ test tube (Cole-Palmer, Vernon Hills, IL) containing $10 \mathrm{ml}$ of water. The tubes were vortexed for $60 \mathrm{~s}$ and filtered through double layers of cheesecloth for retention of media and mycelial fragments. The number of conidia per milliliter of the filtrate was enumerated by using a hemocytometer under a compound microscope. The data were extrapolated to obtain the number of conidia per Petri plate. Two conidial counts were obtained from each sample. This experiment was conducted twice.

Data analysis. Data on the net radial growth and sporulation (conidia per Petri plate) of $C$. janseana were analyzed by generalized mixed linear model analysis (Proc Mixed; SAS 9.4, SAS Institute, Cary, NC) for differences among the media, amendment concentrations of plant extracts, V8 juice supplementation levels, and assessment intervals. Mean separations were performed using Fisher's protected least significant difference test at $P=0.05$. Transformations were performed when data did not fit a normal distribution. After statistical analysis, means were back-transformed to original units.

\section{Results}

Effects of plant-based media and amendment concentrations on radial growth of $\boldsymbol{C}$. janseana (experiment 1). Net radial growth data were logarithmically transformed to meet the criterion for normal distribution. At 7 and $14 \mathrm{DAI}$, significant differences in radial growth were observed among the media $(P<0.0001)$ but not among the plant extract amendment concentrations $(P=0.61)$ or medium by plant extract amendment concentration interactions $(P=0.81)$. Therefore, the data at each interval were pooled over the amendment concentrations of plant extracts (Fig. 1). At both the interval assessments, the media amended with the extracts of fresh rice leaves, dried rice leaves, dried rice stems, dried barnyard grass leaves, and 20\% V8 supported significantly greater radial growth of $C$. janseana (average of 8.2 and $15.1 \mathrm{~mm}$ at 7 and $14 \mathrm{DAI}$, respectively) than the PDA control (average of 5.6 and $8.8 \mathrm{~mm}$ at 7 and $14 \mathrm{DAI}$, respectively).

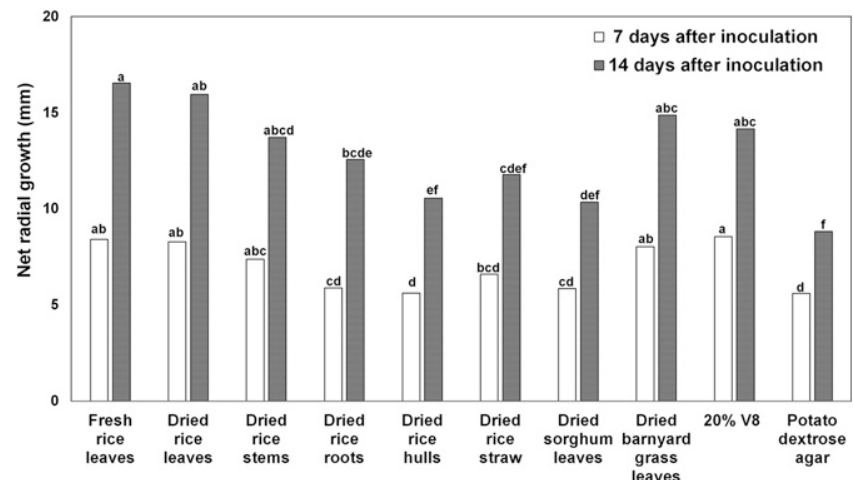

Fig. 1. Radial growth of Cercospora janseana at 7 and 14 days after inoculation on eight plant-based agar media amended with plant extracts (experiment 1). Data were pooled over all amendment concentrations $(25,50,100$, and $200 \mathrm{~g} /$ /iter) of the plant extracts because there were no significant differences in the radial growth among the four concentrations $(P=0.61)$ tested, or their interaction with plantbased media $(P=0.81)(n=9)$. At each of the same assessment dates, bars with different letters were significantly different $(P<0.05)$. 
Effects of plant-based media in combination with $\mathrm{V8}$ juice on radial growth and sporulation of $\boldsymbol{C}$. janseana (experiment 2). Net radial growth data were square-root transformed to normalize the data distribution. At 7 DAI, radial growth differed among the media $(P=0.0025)$, but not owing to V8 supplementation levels $(P=0.77)$ or medium by V8 supplementation interactions $(P=0.45)$. Thus, data from all V8 supplementation levels within a medium treatment were combined (Fig. 2A). All the media with plant extracts and the 10 and

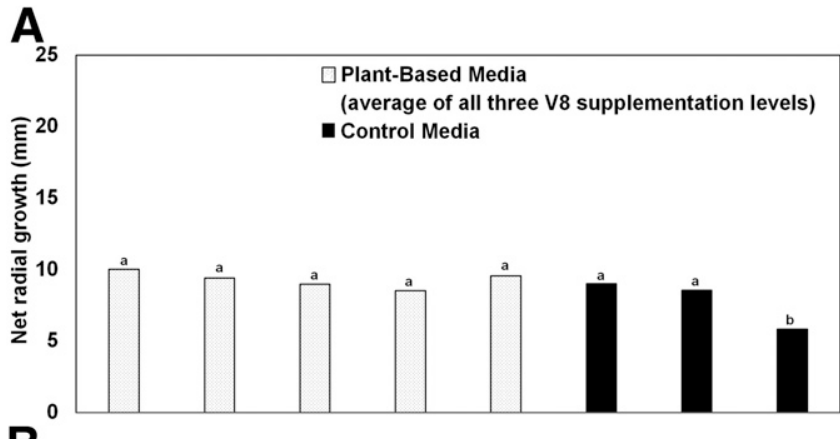

B

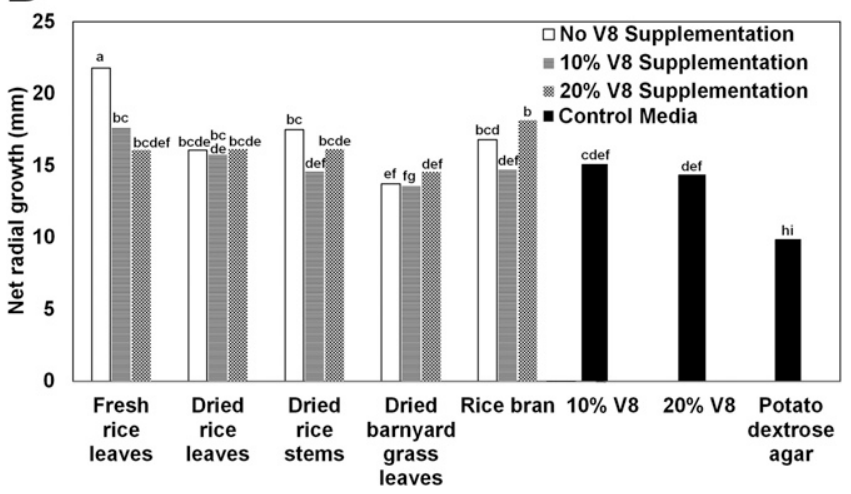

Fig. 2. Effects of five plant-based agar media amended with plant extracts (at $25 \mathrm{~g} /$ liter) in combination with 0,10 , and $20 \%$ of clarified V8 juice on the radial growth of Cercospora janseana at 7 (A) and 14 (B) days after inoculation (DAl) (experiment 2). At $7 \mathrm{DAl}$, data within a medium treatment were pooled over all the three $\mathrm{V} 8$ supplementation levels $(0,10$, and $20 \%$ of $\mathrm{V} 8)$, because there were no significant differences in the radial growth among these three levels $(P=0.77)$ and the interactions of plant-based medium by V8 supplementation $(P=0.45)(n=6)$. At each of the same assessment dates, bars with different letters were significantly different $(P<0.05)$.

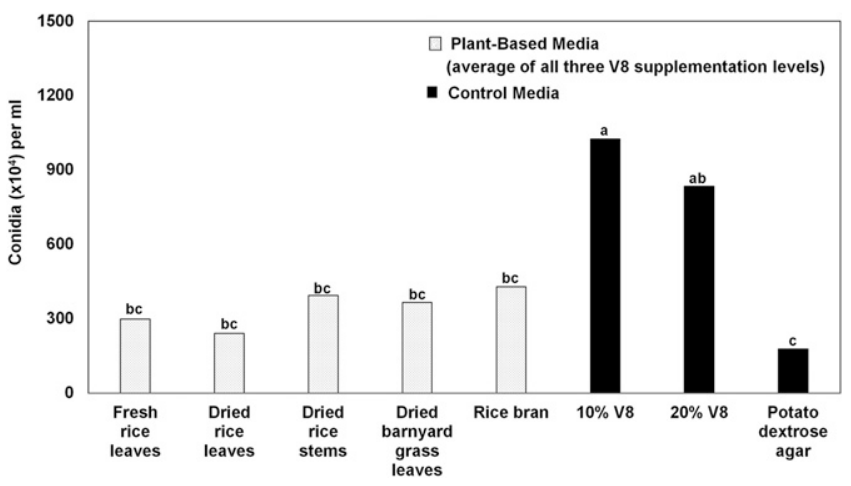

Fig. 3. Effects of five plant-based agar media amended with plant extracts at 25 $\mathrm{g} /$ /iter on sporulation (conidia per plate) of Cercospora janseana at 14 days after inoculation (experiment 2). Data within a medium treatment were pooled over all the three V8 supplementation levels $(0,10$, and $20 \%)$, because there were no significant differences in the sporulation among these three levels $(P=0.48)$ and the interactions of plant-based medium by V8 supplementation $(P=0.97)(n=$ $6)$. Bars with different letters were significantly different $(P<0.05)$.
$20 \% \mathrm{~V} 8$-only media resulted in greater net radial growth (average of $9.1 \mathrm{~mm})$ than the PDA control $(5.8 \mathrm{~mm})$. At 14 DAI, radial growth differed among the media $(P<0.0001)$ and medium by V8 supplementation interactions $(P=0.0383)$, but not owing to V8 supplementation alone $(P=0.06)$. All the plant-based media at all V8 supplementation levels and V8-only media had a greater radial growth (ranged from 13.6 to $21.8 \mathrm{~mm}$ ) compared with the PDA control $(9.8 \mathrm{~mm})$; the greatest radial growth occurred in the medium with fresh rice leaf extract with no V8. Fresh rice leaf extract supplemented with V8 had less radial growth. In other media, V8 supplementation effects were not consistently negative or positive (Fig. 2B).

Sporulation data were natural $\log$ transformed to stabilize the variance. Sporulation differed among the media $(P=0.03)$, but not owing to V8 supplementation levels $(P=0.48)$ or medium by V8 supplementation interactions $(P=0.97)$. Thus, data from all the V8 supplementation levels within a medium treatment were combined. The $10 \%$ V8 medium resulted in greater sporulation than all other media with $1 \times 10^{8}$ spores per plate $(479 \%$ more conidia than the PDA control). The $20 \%$ V8 medium had $8.3 \times 10^{7}$ spores per plate (371\% more conidia than the PDA control) (Fig. 3). Other plantbased media resulted in conidial yields in the range of $2.4 \times 10^{7}$ to $4.3 \times 10^{7}$ spores per plate, whereas the PDA control had a conidial yield of $1.8 \times 10^{7}$ spores per plate. The growth of $C$. janseana in various plant-based media with and without V8 supplementation is presented in Figure 4

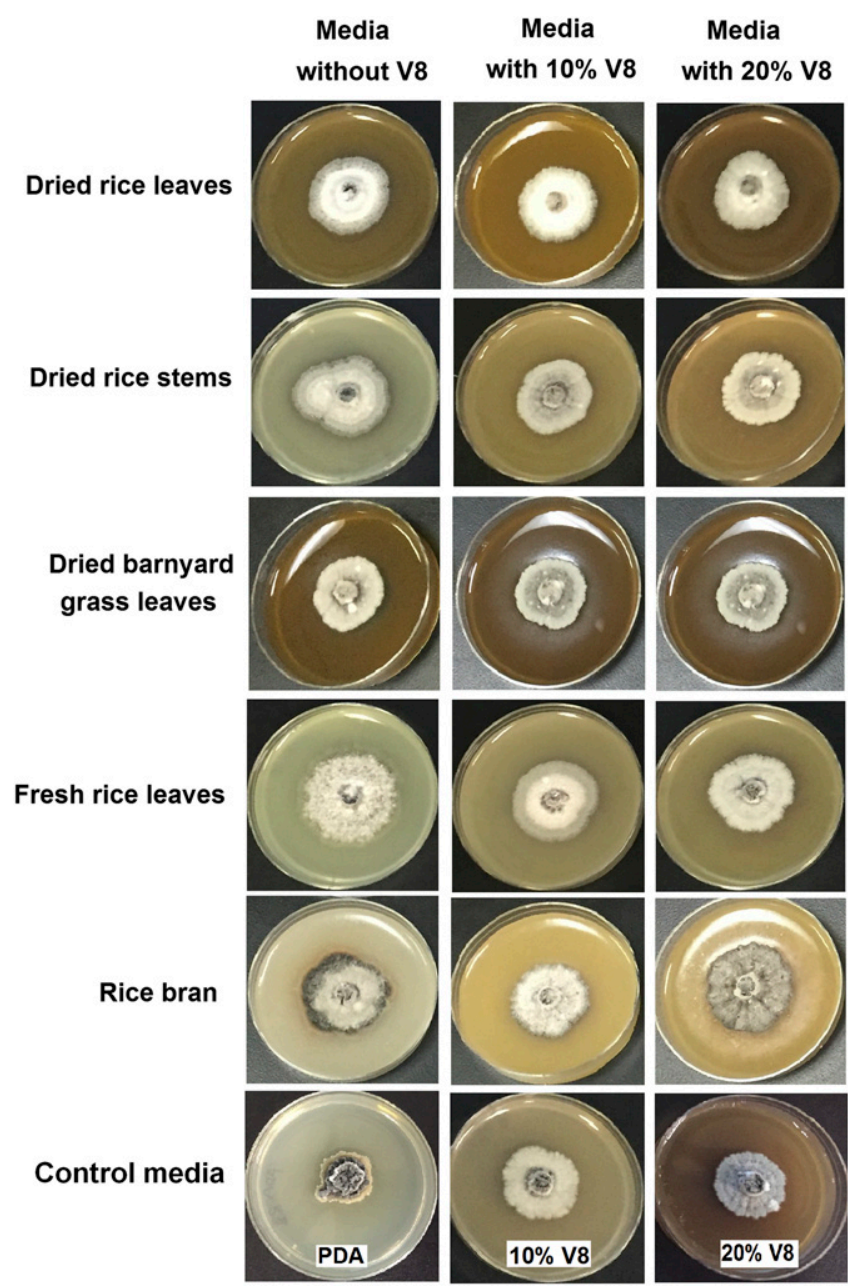

Fig. 4. Colony morphology of Cercospora janseana in agar media amended with five plant extracts at $25 \mathrm{~g} /$ /iter in combination with 0,10 , or $20 \%$ of clarified V8 juice supplementation at 14 days after inoculation (experiment 2). 


\section{Discussion}

The fungus $C$. janseana grows slowly and produces sparse conidia on PDA, commonly used in laboratories. An improved cultural medium that can stimulate growth and sporulation of the fungus could facilitate research on the biology of $C$. janseana, screening rice germplasm for disease resistance, and evaluating various disease management strategies. Several investigators reported improved growth, sporulation, and cultivability of various fungal pathogens and of beneficial endophytic and rhizospheric microorganisms in plant-based culture media (Beckman and Payne 1983; Brunelli et al. 2006; Murphy et al. 2015; Nour et al. 2012; Yadav et al. 2014; Youssef et al. 2016). The current study was initiated with an objective to develop an effective plant-based culture medium for $C$. janseana. For this, we evaluated the extracts obtained from different tissues of the host plant (rice), leaves of nonhost plants such as barnyard grass and sorghum, and commercially available V8 juice at various concentrations in agar medium for their effects on the radial growth and sporulation of $C$. janseana.

Plant-based media with extracts of fresh rice leaves, dried rice leaves, dried rice stems, dried barnyard grass leaves, and V8 juice consistently resulted in greater radial growth compared with PDA throughout the current study. At 7 DAI, media with these four plant extracts and V8 juice resulted in statistically similar radial growth in both experiment 1 and 2 . However, at 14 DAI, in both the experiments, the medium with the extract of fresh rice leaves alone was consistent in supporting greater radial growth than all other media evaluated. Differences in the radial growth between the medium with the extract of fresh rice leaves and media with dried plant products (including dried rice leaves) could be explained by the possible alterations in nutritional profiles owing to drying (Alakali et al. 2015; Clement et al. 2017; Sharma et al. 2004). The reasons for the plant-based media with the extracts of dried rice hulls, dried rice roots, dried rice straw, and dried sorghum leaves being less favorable for the radial growth are unknown, but differences in nutritional composition profiles of these media may be a factor contributing to the different responses (Gao et al. 2007; Griffin 1994; Hawker 1957; Walker and White 2011). Carbon, nitrogen, and phosphorus accumulation is reported to be different among various plant parts, with leaves accumulating more than stems or roots (Tang et al. 2017; Ye et al. 2014). Concentrations of carbon, nitrogen, carbon/ nitrogen ratio, vitamins, and minerals in culture media have been known to affect the growth and sporulation of other fungi (Gao et al. 2007; Griffin 1994; Hawker 1957; Walker and White 2011). In experiment 1 , when the extracts from 25 to $200 \mathrm{~g} /$ liter were evaluated, no significant increase in radial growth was observed with an increase in the concentration of plant material beyond $25 \mathrm{~g} /$ liter. Thus, $25 \mathrm{~g} /$ liter can be concluded as high enough concentration for enhancing radial growth to the levels reported in the current study.

At 2 weeks after inoculation, net radial growth in media with plant extracts was in the range of 10 to $22 \mathrm{~mm}$. In PDA and V8 media, average net radial growth was 10 and $15 \mathrm{~mm}$, respectively. At $17 \mathrm{DAI}$, when incubated at $28^{\circ} \mathrm{C}$ under a $12 / 12$-h (fluorescent light/dark) cycle, Mew and Gonzales (2002) reported C. janseana diameters of 14 and $23 \mathrm{~mm}$ on PDA and V8 agar media, respectively. However, direct comparisons cannot be made with our study because they did not provide details on the size of the initial inoculum discs or concentrations of V8 juice in the culture medium.

Greater sporulation was observed in $10 \%$ V8 medium (with average conidial yields of $1 \times 10^{8}$ per Petri plate) than in all other media. The current study is the first to report conidial yields of $C$. janseana in culture media. Beckman and Payne (1983) reported $2.4 \times 10^{5}$ conidia per plate on $30 \% \mathrm{~V} 8$ medium at $14 \mathrm{DAI}$ of $C$. zeae-maydis. Brunelli et al. (2006) reported $2.2 \times 10^{6}$ conidia per plate (or $22.4 \times 10^{4}$ conidia/ml of harvested spore suspension) of C. zeae-maydis on $20 \%$ V8 medium at 9 DAI. The current study differs from Beckman and Payne (1983) and Brunelli et al. (2006) in that they used higher concentrations of V8 compared with our study; they harvested spores by adding $10 \mathrm{ml}$ of sterile water and scraping the surface of the agar medium with a sterile glass slide, whereas we employed the whole mycelia harvest technique. Unlike the current study, for which prior clarification of $\mathrm{V} 8$ juice was performed with $1 \% \mathrm{CaCO}_{3}$ before preparation of media, Brunelli et al. (2006) and Beckman and Payne (1983) incorporated 0.32 and $0.4 \% \mathrm{CaCO}_{3}$ directly to 20 and $30 \%$ V8 media, respectively. While we evaluated 10 and $20 \%$ V8 juice individually and in combination with plant extracts, Beckman and Payne (1983) and Brunelli et al. (2006) tested a single concentration of V8 juice in agar medium.

When the plant extracts were evaluated in combination with 10 and $20 \% \mathrm{~V} 8$, none of the plant extract and V8 amendment combinations had any additional stimulating effect on the radial growth of $C$. janseana than the media without V8 amendment. In media with the extracts of fresh rice leaves, V8 juice supplementation resulted in significant reduction in radial growth. In other plant-based media, the effects of V8 juice supplementation were not consistently negative or positive. With reference to sporulation, agar media with individual plant extracts either alone or in combination with V8 did not result in enhanced sporulation compared with the media with V8 juice alone or the PDA control. This indicates that the addition of plant extracts to V8 had a negative effect on sporulation. The current study is the first to evaluate V8 juice in combination with plant extracts for radial growth and sporulation of fungi.

In the current study, C. janseana was incubated under 12/12-h (light/dark) cycle, because this was reported to induce more sporulation of other Cercospora species compared with constant light (Beckman and Payne 1983; Brunelli et al. 2006; Gómez and Reis 2013; Latterell and Rossi 1983). Incubation temperature and medium $\mathrm{pH}$ affect the growth and sporulation of Cercospora species (Beckman and Payne 1983; Brunelli et al. 2006; Cooperman and Jenkins 1986; Djebali et al. 2010; Gómez and Reis 2013; Silva et al. 2016; Tasugi and Ikeno 1956; Verma and Agnihotri 1972). The optimum temperature and $\mathrm{pH}$ for the growth of $C$. janseana were reported to be 25 to $28^{\circ} \mathrm{C}$ and 5.7 to 7.1 , respectively (Tasugi and Ikeno 1956). In the current study, $C$. janseana was incubated at $28^{\circ} \mathrm{C}$, and the $\mathrm{pH}$ values of various agar media (data not presented) ranged from 5.7 to 6.8 , which is within the optimum range. Further studies on the effects of culture medium $\mathrm{pH}$, light regimes, the time required for sporulation initiation in vitro, and nutrient composition of effective plant-based media might provide a better understanding of the optimum cultural conditions for C. janseana. One of the limitations of the current study is that only one isolate of $C$. janseana was evaluated for radial growth and sporulation. The inclusion of multiple isolates could have addressed variation among the isolates, if any, in any specific culture medium.

The results of this research demonstrate that medium with fresh rice leaf extract amendment at $25 \mathrm{~g} /$ liter is the best medium to improve the radial growth of $C$. janseana, and $10 \% \mathrm{~V} 8$ medium is the best medium to improve the sporulation of the fungus.

\section{Acknowledgments}

We thank student interns Linda Zhou, Lunan Jin, Guobing Xia, and Wenhui Gao for their assistance in conducting this research.

\section{Literature Cited}

Abdou, Y. A. M., and Cooper, W. E. 1974. Effect of culture medium and light on sporulation of two peanut leaf spotting fungi, Cercospora arachidicola Hori and Cercosporidium personatum (Beck \& Curtis). Deighton. Peanut Sci. 1: 11-14.

Alakali, J. S., Kucha, C. T., and Rabiu, I. A. 2015. Effect of drying temperature on the nutritional quality of Moringa oleifera leaves. Afr. J. Food Sci. 9:395-399.

Basu, S., Pal, A., and Desai, P. K. 2005. Quality control of culture media in a microbiology laboratory. Indian J. Med. Microbiol. 23:159-163.

Beckman, P. M., and Payne, G. A. 1983. Cultural techniques and conditions influencing growth and sporulation of Cercospora zeae-maydis and lesion development in corn. Phytopathology 73:286-289.

Brunelli, K. R., Fazza, A. C., Sobrinho, A. C., and Camargo, L. E. A. 2006. Efeito do meio de cultura e do regime de luz na esporulação de Cercospora zeaemaydis. Summa Phytopathol. 32:92-94.

Chilton, S. J. P., and Tullis, E. C. 1946. A new race of Cercospora oryzae in rice. Phytopathology 36:950-952.

Clement, A., Olatunde, M., Patrick, O., and Joyce, O. 2017. Effect of drying temperature on nutritional content of Moringa oleifera leave. World J. Food Sci. Techol. 1:93-96. 
Constantinescu, O. 1982. Studies on Cercospora and similar fungi. II. New combinations in Cercospora and Mycovellosiella. Cryptogam., Mycol. 3:63-70.

Cooperman, C. J., and Jenkins, S. F. 1986. Conditions influencing growth and sporulation of Cercospora asparagi and Cercospora blight development in asparagus. Phytopathology 76:617-622.

Djebali, N., Gaamour, N., Badri, M., and Aouani, M. E. 2010. Optimizing growth and conidia production of Cercospora medicaginis. Phytopathol. Mediterr. 49: 267-272.

El-Gholl, N. E., Alfieri, S. A., Jr., Ridings, W. H., and Schoulties, C. L. 1982. Growth and sporulation in vitro of Cercospora apii, Cercospora arachidicola, Cercospora kikuchii, and other species of Cercospora. Can. J. Bot. 60:862-868.

Estrada, B. A., Sanchez, L. M., Nuque, F. L., and Crill, J. P. 1981. Physiological races of Cercospora oryzae in the Philippines. Plant Dis. 65:793-795.

Ferguson, A. J., and Jeffers, S. N. 1999. Detecting multiple species of Phytophthora in container mixes from ornamental crop nurseries. Plant Dis. 83:1129-1136

Ganguly, D. 1946. A note on occurrence of Cercospora oryzae Miyake on paddy in Bengal. Sci. Cult. 11:573-574.

Gao, L., Sun, M. H., Liu, X. Z., and Che, Y. S. 2007. Effects of carbon concentration and carbon to nitrogen ratio on the growth and sporulation of several biocontrol fungi. Mycol. Res. 111:87-92.

Gómez, D. E., and Reis, E. M. 2013. Influence of substrates, light, filter paper and $\mathrm{pH}$ on the sporulation of Cercospora sojina. Summa Phytopathol. 39:126-129.

Griffin, D. H. 1994. Fungal Physiology, 2nd Ed. Wiley-Liss, New York, NY.

Groth, D. E. 2008. An epidemic of NBLS on rice in 2006 in Louisiana and its control. Proc. Rice Tech. Wrkg. Grp. 32:85.

Groth, D. E. 2007. The narrow brown leaf spot outbreak and its control in 2007. https://www.laca1.org/Presentations/2007/Rice-Groth.pdf. LSU Rice Research Station, Crowley, LA.

Groth, D. E., and Lee, F. 2003. Rice diseases. Pages 413-436 in: Rice: Origin, History, Technology, and Production. C. W. Smith and R. H. Dilday, eds. Wiley, Hoboken, NJ.

Hawker, L. E. 1957. The Physiology of Reproduction in Fungi. Cambridge University Press, Cambridge, U.K.

Jha, S., and Dikshit, S. N. 2017. Alternative culture media for fungal growth using different formulation of plant material. Int. J. Pharma Bio Sci. 8:445-452.

Kaur, K., and Hollier, C. 2013. Effect of amended media, temperature, and light on the growth and development of Cercospora janseana. American Phytopathological Society annual meeting, Austin, TX.

Latterell, F. M., and Rossi, A. E. 1983. Gray leaf spot of corn: A disease. Plant Dis. 67:842-847.

Mani, K. K., Hollier, C. A., and Groth, D. E. 2016. Effect of planting date, fungicide timing and cultivar susceptibility on severity of narrow brown leaf spot and yield of rice. Crop Prot. 90:186-190.

Metcalf, H. 1906. A preliminary report on the blast of rice, with notes on other rice diseases. Bull. S. C. Agric. Experiment Stn. 121:1-43.

Mew, T. W., and Gonzales, P. 2002. A Handbook of Rice Seedborne Fungi. International Rice Research Institute, Los Baños, Philippines.

Miyake, I. 1910. Studien über die Pilze der Reispflanze in Japan. J. Coll. Agric. Imp. Univ. Tokyo 2:237-276.

Murphy, B. R., Batke, S., Doohan, F. M., and Hodkinson, T. R. 2015. Media manipulations and the culture of beneficial fungal root endophytes. Int. J. Biol. 7:94-102.

Nour, E. H., Hamza, M. A., Fayez, M., Monib, M., Ruppel, S., and Hegazi, N. A. 2012. The crude plant juices of desert plants as appropriate culture media for the cultivation of rhizospheric microorganisms. J. Adv. Res. 3:35-43.

Osman, Z. A., Elsanousi, S. M., and Elsheikh, E. A. E. 2013. Plant materials as probable growth promoters for certain fungi. Asian J. Plant Sci. Res. 3:87-93.

Ou, S. H. 1985. Rice plant diseases. Pages 227-231 in: Rice Production and Utilization. B. S. Luh, ed. AVI Publishing, Westport, CT.
Overwater, C. 1960. Tien Jaren Prins Bernhard polder, 1950-1960. Surinaamse Landbouw 8:159-218. [Rev. Appl. Mycol. 40:465, 1961.]

Raciborski, M. 1900. Parasitische Algen und Pilze Javas, Vol. II. Botanisches Institut, Buitenzorg, Indonesia.

Ryker, T. C., and Jordon, N. E. 1940. Inheritance of resistance to Cercospora oryzae in rice. Phytopathology 30:1041-1047.

Sah, D. N., and Rush, M. C. 1988. Physiological races of Cercospora oryzae in the southern United States. Plant Dis. 72:262-264.

Secor, G. A., and Rivera, V. V. 2012. Fungicide resistance assays for fungal plant pathogens. Pages 385-392 in: Plant Fungal Pathogens: Methods in Molecular Biology. M. Bolton and B. Thomma, eds. Humana Press, Totowa, NJ.

Sharma, H. R., Chauhan, G. S., and Agarwal, K. 2004. Physico-chemical characteristics of rice bran processed by dry heating and extrusion cooking. Int. J. Food Prop. 7:603-614.

Silva, M. G. D., Pozza, E. A., Monteiro, F. P., and de Lima, C. V. R. V. 2016 Effect of light and temperature on Cercospora coffeicola and Coffea arabica pathosystem. Coffee Sci. 11:148-160.

Starkey, T. E. 1980. A simplified medium for growing Cercospora arachidicola. Phytopathology 70:990-991.

Tang, Z., Xu, W., Zhou, G., Bai, Y., Li, J., Tang, X., Chen, D., Liu, Q., Ma, W. Xiong, G., He, H., He, N., Guo, Y., Guo, Q., Zhu, J., Han, W., Hu, H., Fang, J., and Xie, Z. 2017. Patterns of plant carbon, nitrogen, and phosphorus concentration in relation to productivity in China's terrestrial ecosystems. Proc. Natl. Acad. Sci. U.S.A. 115:4033-4038.

Tasugi, H., and Ikeno. S. 1956. Studies on the morphology, physiology and pathogenicity of Cercospora oryzae Miyake, the causal fungus of narrow brown leaf spot of rice plant. Bull. Natl. Inst. Agric. Sci. Tokyo C6:167-178.

Tuli, F. U., Hossain, M. I., Shapla, S. A., Hussain, M. A., Talukdar, M. R. B., Kawochar, A., and Ferdous, J. 2017. Efficacy of selected fungicides in controlling foliar diseases of rice (Oryza sativa L.). J. Plant Sci. 5:185-190.

Uppala, S., and Zhou, X. G. 2018. Field efficacy of fungicides for management of sheath blight and narrow brown leaf spot of rice. Crop Prot. 104:72-77.

Verma, P. R., and Agnihotri, J. P. 1972. Effect of nutrition, $\mathrm{pH}$ and temperature on growth and sporulation of Cercospora cruenta Sacc. and Cercospora beticola Sacc. Phytopathol. Mediterr. 11:25-29.

Walker, G. M., and White, N. A. 2011. Introduction to fungal physiology. Pages 1-35 in: Fungi: Biology and Application. K. Kavanagh, ed. Wiley, Hoboken, NJ.

Yadav, R. S., Tyagi, S., Javeria, S., and Gangwar, R. K. 2014. Effect of different cultural conditions on the growth of Fusarium moniliforme causing Bakanae disease. Eur. J. Mol. Biotec. 4:95-100.

Ye, Y., Liang, X., Chen, Y., Li, L., and Ji, Y. 2014. Carbon, nitrogen and phosphorus accumulation and partitioning, and $\mathrm{C}: \mathrm{N}: \mathrm{P}$ stoichiometry in lateseason rice under different water and nitrogen managements. PLoS ONE 9: e101776.

Yingling, J. A., Cartwright, R. D., Parsons, C. E., Sutton, E. A., Wilson, C. E., Smith, S., Jr., Carroll, A. G., Lee, F. N., Gibbons, J. W., and Moldenhauer, K. A. K. 2007. Evaluation of rice germplasm for reaction to disease across Arkansas. Pages 163-177 in: B. R. Wells Rice Research Studies 2006. R. J. Norman., J.-F. Muellenet, and K. A. K. Moldenhauer, eds. Research Series 550. Arkansas Agricultural Experiment Station, University of Arkansas, Fayetteville, AR.

Youssef, H. H., Hamza, M. A., Fayer, M., Mourad, E. F., Saleh, M. Y., Sarhan, M S., Suker, R. M., Eltahlawy, A. A., Nemr, R. A., El-Tahan, M., Ruppel, S., and Hegazi, N. A. 2016. Plant-based culture media: Efficiently support culturing rhizobacteria and correctly mirror their in-situ diversity. J. Adv. Res. 7:305-316.

Zhou, X. G., and Jo, Y. K. 2014. Disease management. Pages 44-57 in: 2014 Texas Rice Production Guidelines. M. O. Way, G. M. McCauley, X. G. Zhou, L. T. Wilson, and M. Brandy, eds. B-6131. Texas A\&M AgriLife Research, and Texas Rice Research Foundation, Beaumont, TX. https://beaumont.tamu.edu/ eLibrary/Bulletins/2014_Rice_Production_Guidelines.pdf 